УДК: $165+167+168$

\title{
Елена КНЯЗЕВА
}

\section{КОГНИТИВНЫЕ СЕТИ: ИНТЕРАКТИВНОСТЬ, ИНТЕРСУБЪЕКТИВНОСТЬ, СИНЕРГИЯ ${ }^{1}$}

В статье обсуждаются некоторые свойства когнитивных сетей в контексте современных достихений науки о сетях (Network

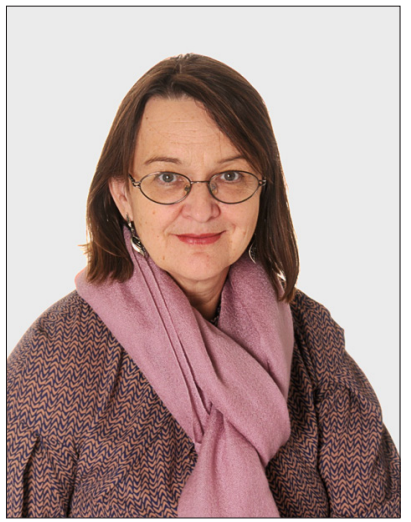
Science). Именно исследование сетевых структур и их удивительных свойств придает сегодня новый импульс развитию теории сложных систем (синергетики). Анализ познавательных процессов с точки зрения возникающих в них сетевых структур не только сопрягается с уже существуюшими в когнитивной науке и эпистемологии понятиями (когнитивная ниша, когнитивная карта, когнитивная когерентность и m.n.), но и привносит некоторые новые аспекты в понимание интерактивности, интерсубъективности, синергии в познании и творчестве, эмпатии.

Ключевые слова: автономия, зеркальные нейроны, интерсубъективность, когнитивные сети, когнитивные ниши, партисипационное производство смыслов, сетевые структуры, сложность, эмпатия, энактивизм.

2017 год является юбилейным для теории сложных систем (синергетики) как междисциплинарного направления исследований. Не только философия, но и наука, особенно такая находящаяся в становлении наука, как наука о сложности, персонифицирована. В этом году исполняется 100 лет со дня рождения Ильи Пригожина (1917-2003), 90 лет со дня рождения Германа Хакена (р. 1927), а также 70 лет со дня рождения украинского философа, международно известного специалиста в области философии сложности Ирины Добронравовой ${ }^{2}$ (р. 1947). Будучи укорененной в исследованиях гомеостазиса (отрицательных обратных связей) в функционировании физиологических систем организма человека (К. Бернар, У.Б. Кеннон) и в эволюционных идеях в биологии (Ч. Дарвин), теория сложности развивалась с 1940-х годов в работах И.

\footnotetext{
${ }^{1}$ Исследование выполнено при поддержке РГНФ (проект № 15-03-00860a «Meтодология управления сетевыми структурами в контексте парадигмы сложности»).

2 Добронравова И.С. Синергетика: становление нелинейного мышления. Киев: Лыбидь, 1990.
} 
Пригожина по неравновесной термодинамике, с 1950-х годов в исследованиях в области физики лазера Г. Хакена, который ввел в научный оборот сам термин «синергетика» и разработал классический концептуальный аппарат синергетики как научной парадигмы, с 1960-х годов в исследованиях С.П. Курдюмова ${ }^{1}$ и его научной школы в области управляемого термоядерного синтеза, математического моделирования нелинейных процессов в диссипативных средах и собственно синергетики как теории возникновения, трансформации и эволюции структур в режимах с обострениями в нелинейных средах. В настоящее время появляются новые направления исследований в области теории сложности. Одна из них - это наука о сетях (Network Science), о сетевых структурах, существенный вклад в развитие которой внес талантливый венгерский ученый, возглавляющий в настоящее время научную исследовательскую группу в США А.-Л. Барабаши². Как всякая историческая веха 2017 год заставляет нас критически оценить пройденный исторический путь в углублении нашего понимания функционирования и эволюции сложных систем и задуматься о путях дальнейшего развития теории сложности и методологии междисциплинарных исследований в науке в целом.

\section{0 некоторых нетривиальных свойствах сетевых структур}

Сети как адаптивные системы. Немаловажный вклад в понимание феномена сложности мира, в котором мы живем, вносит современная теория сложных адаптивных систем (М. Гелл-Манн, Дж. Холланд и др.) и наука о сетевых структурах (А.-Л. Барабаши). В то время как сложные системы существуют на всех уровнях бытия, начиная с уровня неживой природы, сложные адаптивные системы - это системы биологические, человеческие, социальные, информационные, коммуникативные, ноосферные. К таковым относятся организации, которые возникают в сообществах общественных животных (например, муравейник), биосфера и экосистемы, мозг, иммунная система, клетка и эмбрион, такие социальные системы, как экономические рынки, биржи, политические партии, общественные организации и ассоциации, научные и культурные сообщества как сложные когнитивные и коммуникативные сети.

По выражению А.-Л. Барабаши, «основанные на базах данных математические модели сложных систем открывают нам свежую перспекти-

${ }^{1}$ О личности С.П. Курдюмова и его идеях, важных для становления методологии междисциплинарных исследований см.: Мне нужно быть. М.: КРАСАНД, 2010; Князева Е.Н., Куркина Е.С. Мыслитель эпохи междисциплинарности // Вопросы философии. 2009, № 9. С. 116-131.

${ }^{2}$ Barabasi A. - L. Linked. How Everythinf Is Connected to everything else and What It Means for Business, Science, and Everyday Life. N.-Y.: Basic Books, 2014. 
ву, которая быстро развивается в новую дисциплину - науку о сетях» ${ }^{\text {. }}$ Сегодня становится очевидным, что наука о сетях необходима для дальнейшего продвижения в изучении сложных систем. «Мы никогда не поймем функционирование клетки, если мы не придадим значения замысловатым и сложным сетевым структурам, посредством которых клеточные белки и промежуточные продукты обмена веществ взаимодействуют друг с другом внутри клетки. Мы никогда не сможем предсказать экономических банкротств, пока мы не набросаем схему сети долговых обязательств, которые характеризуют экономическую систему. Эти глубокие изменения в исследованиях сложности представляют собой эхо значительных экономических и социальных сдвигов. Экономическими гигантами нашей эры являются уже не производители машин и нефтяные концерны, а компании, которые строят, управляют и снабжают топливом наши сетевые структуры: Сиско, Гугл, Фейсбук, Эппл или Твиттер. И как следствие этого в течение последнего десятилетия наука о сетях похищала у исследований сложности вопрос за вопросом, систему за системой» ${ }^{2}$.

Активная адаптация. Сетевые структуры демонстрируют свойство адаптации, поэтому относятся к классу сложных адаптивных систем. Причем адаптация не пассивна, а активна. Это не простое приспособление, не какая угодно гибкость, а создание под себя своей собственной среды, соответствующего своим поведенческим стратегиям окружения. Сетевые структуры способны самообучаться, т.е. корректировать свои действия в зависимости от результатов предыдущих действий, активно встраиваться в среду, приспосабливаясь к ней и изменяя ее в ходе своей активности. Методология организации сложных адаптивных систем и управления ими может строиться на понимании их фундаментальных свойств: самоподобия (пространственной и временной масштабной инвариантности), активной адаптации к сложной окружающей среде, сопряжения самоорганизации и эмерджентности.

Самоподобие есть свойство фрактальной организации, когда формы связи, адаптации, типы власти или коммуникации повторяют друг друга на разных иерархических уровнях организации системы. Самоподобие, или масштабная инвариантность, может быть и пространственной, и временной. В последнем случае самоподобие означает вложенность циклов развития системы, когда циклы накладываются на циклы. Это так называемая гнездящаяся эволюция (nested evolution). Сложность адаптивной системы определяется не просто множеством элементов систе-

\footnotetext{
${ }^{1}$ Barabási A.-L. The Network Takeover // Nature Physics. 2012. Vol. 8. P. 14.

${ }^{2}$ Ibid. P. 15.
} 
мы, но и тем, что ее элементы (и подсистемы) являются автономными агентами, которые способны к взаимодействию, адаптации и обучению.

Важнейшими свойствами сложной адаптивной системы являются также адаптация, коммуникация (на всех уровнях, от элементов до уровня системы как целого), специализация, пространственно-временная организация. Адаптация является активной: имеет место не только адаптация элементов друг к другу, их ко-адаптация, но и адаптация системы к среде.

Один из наиболее известных исследователей в этой области, профессор психологии и компьютерной науки Джон Г. Холланд в своей книге «Скрытый порядок: как адаптация строит сложность» (1995) называет следующие свойства сложных адаптивных систем: агрегация, нелинейность, поток, разнообразие, а в качестве механизмов их организации выделяет теги, внутренние модели и составные блоки ${ }^{1}$. Агрегирующийся агент, как правило, находится вне системы, элементы которой уже хорошо адаптированы друг к другу. Включение этого агента системы не так просто, оно часто бывает связано с созданием иного, более высокого уровня организации, т.е. радикальной перестройкой всей системы. Нелинейность взаимодействия между элементами (автономными агентами) делает их взаимодействие все более сложным и непредсказуемым. Нелинейность связана и с пороговостью чувствительности к возмущениям и с возможностями разрастания малых флуктуаций в состоянии нестабильности. Для сложных адаптивных систем характерны потоки (поток товаров, поток информации и т.п.). В более сложных случаях мы имеем дело с потоками по сетям с узлами и более мощными узлами - хабами - коннекторами (соединителями). В качестве узлов в сложной сети могут выступать предприятия, а в качестве коннекторов - транспортные пути, по которым движутся материальные ресурсы или товары между ними.

Существенное свойство сложной адаптивной системы - разнообразие ее элементов (подсистем). Поддержание разнообразия элементов является основой динамической устойчивости системы в целом. Это известный принцип необходимого разнообразия элементов У. Росс Эшби. Что означает разнообразие? В тропическом лесу мы можем пройти километр и не встретить на своем пути дважды ни один из биологических видов, настольно богата вариациями экосистема тропического леса. Мозг млекопитающего - это сложно организованная иерархическая сеть нейронов со сложной морфологией. Нью-Йорк - это мегаполис со сложнейшей сетью оптовых и розничных продавцов и по-

${ }^{1}$ Holland J.H. Hidden Order: How Adaptation Builds Complexity. Readings (MA): Addison-Wesley Publishing Company, 1995. P.38. 
купателей. Внутреннее разнообразие в сложной адаптивной системе не является случайным. Каждый автономный агент занимает в ней свою экологическую, рыночную, когнитивную и т.п. нишу. Новый агент, как правило, занимает нишу исчезнувшего агента, возобновляя и поддерживая те связи, которые были наработаны его предшественником.

Механизмом организации сложной адаптивной системы является тегирование, создание тегов. Это, например, создание баннеров, слоганов, флажков, имиджа, которые определяют принадлежность к определенной фирме, предприятию, партии или сообществу. Внутренние модели - это схемы, образцы, паттерны поведения, сложившиеся для сложной адаптивной системы. Они определяют и способы антиципации будущего. Сложная адаптивная система строится из крупных блоков, кластеров, ее подсистемы - это мета-агенты, поведение которых может быть подобным поведению агентов.

Удивительные свойства сетевых структур. При анализе сетевых структур обычно выделяют следующие свойства: густота сети, ее размер, средняя длина расстояния между двумя узлами, диаметр сети, коэффициент создания кластеров, связность (connectedness), мера центральности узла в сети (вес узла).

Основные концептуальные элементы науки о сетях можно найти в книгах А.-Л. Барабаши ${ }^{1}$. Мера центральности узлов в сети разная. Большие узлы растут быстрее, чем средние и малые. Если сетевая структура достраивается новым узлом, то узлы с большим количеством связей растут быстрее, поскольку они лучше встроены в сеть и более значимы, имеют больший вес для всей сети. Рост узлов сетевой структуры - это нелинейный процесс: крупные узлы быстро становятся еще крупнее, богатые делаются еще богаче, слава уже прославившихся возрастает быстрыми темпами, крупные научные центры как узлы когнитивных сетей привлекают наибольшее количество наиболее сильных специалистов в своей области. Члены социальных сетей, имеющие больше всего друзей и подписчиков, получают несравненно больше предложений от новых и все более отдаленных членов дружить или быть в контакте. Барабаши называет этот эффект предпочтительными направлениями установления связей. И напротив, выпадение из сетевой структуры крупных узлов подвергает значительному риску существование всей структуры или, по меньшей мере, весьма болезненно ею переносится, возможности самодостраивания (самоорганизации) сетевой структуры при ликвидации крупных узлов, держащих большое число связей, могут оказаться довольно ограниченными.

${ }^{1}$ См., например: Barabási A.-L. Linked: How Everything is Connected to Everything Else and What It Means for Business, Science and Everyday Life. N.-Y.: Basic Books, 2014. 
В сетях происходят также фазовые переходы. Переход через некий порог означает кризис всей системы (прохождение момента опрокидывания). Тогда все узлы сетевой структуры претерпевают фазовый переход и начинают функционировать как единое целое. Примером может служить закипание воды. Кипение начинается с образования отдельных пузырьков, прохождение порога (момента опрокидывания) означает переход к интенсивному испарению жидкости снаружи и изнутри. Это и есть бурное кипение. Сам факт существования пороговых значений и изменение характера функционирования при переходе через низ означает также нелинейность функционирования сетей как сложных адаптивных структур.

Большинство социальных, биологических, компьютерных, коммуникативных сетевых структур довольно устойчивы к неблагоприятным внешним воздействиям. Если компьютерный вирус распространяется в сети предприятия и поражает $10 \%$ ее узлов, то это обычно не является губительным для этой сети, так как $80 \%$ этих узлов обладают незначительным весом, значимостью для всей сети. Но если вирус поражает $20 \%$ крупных узлов, это может иметь катастрофические последствия для всей сети.

Понимаемые на сегодняшний день свойства функционирования сложных сетей имеют некоторые методологические следствия для успешного ведения бизнеса. Предприятия и фирмы, конкурируя или сотрудничая друг с другом, также выстраиваются в определенные сетевые структуры. Компании и фирмы, которые развивают свой бизнес как войну со своим окружением, причиняют тем самым вред самим себе. И, напротив, компании и фирмы, которые стремятся встроиться в промышленные и маркетинговые сети, устанавливают множество контактов и связей с другими компаниями и формами, поставщиками, клиентами разных уровней, властными структурами, будут развиваться и расти, так как каждый узел с большим количеством связей имеет больше возможностей для расширения своих связей и увеличения своего веса, меры централизации в растущей сети. Кроме того, группа сотрудничающих компаний способна претерпеть фазовый переход и обозначить возникновение новой отрасли производства, услуг, технологий в обществе.

Граница разделяющая и связывающая: сложная сеть в сложном окружении. Особую роль играет понятие границы. Граница - это способ обособления системы (или сетевой структуры) от среды и поддержания ее идентичности и вместе с тем способ связи ее средой. Границы между системой и средой подвижны и полунепроницаемы. Выражаясь на языке теории автопоэзиса, созданной У. Матураной и Ф. Варелой для 
выражения сущности жизни, сложные адаптивные системы являются операционально (или организационно) замкнутыми системами. Такого рода сложные системы одновременно и отделены от окружающего мира, и связаны с ним. Их границы подобны мембранным оболочкам, которые являются границами соединения/разделения. Мембрана позволяет такой системе быть открытой миру, брать из окружающей среды нужные вещества и информацию и быть обособленной от него, во всех своих трансформациях и превращениях поддерживать свою целостность, сохранять свою идентичность. Возрастание сложности системы означает возрастание степени избирательности системы (в ее взаимодействии с окружающей средой, в восприятии и действии, в творчестве и т.д.) и ее операциональной замкнутости.

Живые системы демонстрируют свойство «структурного детерминизма». То, что мы, живые существа, являемся структурно детерминированными системами, означает, что ничто внешнее для нас по существу не может детерминировать то, что происходит в нас самих. «Все, что случается в нас и с нами, происходит как поток структурных изменений, детерминированный в нас момент за моментом посредством внутренней структурной динамики... Автопоэтическая система живет как закрытая структурно детерминированная система в замкнутой динамике структурных изменений» ${ }^{1}$, - разъясняет нам Матурана. И отсюда вытекает когнитивное следствие. Внешний мир, который наблюдатель видит вокруг отдельной живой системы, не существует в таком виде для нее. Наблюдатель и живой организм живут в разных когнитивных мирах, в первую очередь в разных мирах восприятия. И в этом люди как живые существа ничем не отличаются от других живых существ. У нас также есть свой мир, и не только мир восприятия, но и мир ментальных конструктов.

Структурное сопряжение - понятие, введенное Матураной и Варелой, которое в дальнейшем использовал и развивал немецкий философ и социолог Н. Луман. Главное следствие структурного сопряжения состоит в том, что система либо находит себя в этом непрерывном потоке операциональной конгруэнтности со средой, которая изменяется соразмерно с ней, либо не находит и тогда умирает. Поэтому, по мнению Матураны, мы не можем заявлять, что мы знаем что-то независимо от того, что мы делаем и как мы вписаны в окружающую среду. Выражаясь образным языком, сложная адаптивная система, возникнув и развиваясь, испытывает мир, бросает ему вызов, но и мир оказывает влияние на нее. И система, и окружающая среда обоюдно активны. Если процесс их

${ }^{1}$ Maturana H.R. Self-consciousness: How? When? Where? // Constructivist Foundations. 2006. Vol. 1. N 3. P. 93. 
взаимного испытания не завершается распадом системы, то в результате они оказываются взаимно структурно подогнанными друг к другу. Система активно адаптируется к окружающей среде, которая в свою очередь также видоизменяется как бы «навстречу ей». Процесс налаживания их сосуществования, обустройства их совместной «жизни» называют процессом коэволюции, а результатом этого процесса и есть структурное сопряжение сложной системы и среды (в живой природе - организма и среды его обитания).

\section{2. Когнитивные ниши: операциональная замкнутость когнитивных субъектов}

Подлинная и действенная интерсубъективность может строиться только, если в процессе познания участвуют автономные, самостийные, самодостаточные, свободные личности. Здесь проявляет себя известный системный принцип: устойчивость самоорганизующегося целого строится через поддержание внутреннего разнообразия элементов (частей, подструктур). Если на уровне элементов разнообразие нивелируется, подвергается угрозе и динамическая устойчивость целого. Если применить этот принцип к социальному познанию, то личностная самодостаточность и самоопределение взаимодействующих субъектов познания - их автономия, - избыточное производство смыслов на уровне индивидов повышает устойчивость сообщества (группы, коллектива) к выбору благоприятных вариантов будущего, адаптивные возможности сообщества, вероятность принятия эффективных и истинных решений и действий.

Автономия является основным свойством автопоэтических систем, каковыми являются живые системы и социальные системы. Автопоэзис

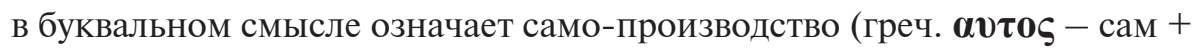
$\boldsymbol{\pi} \boldsymbol{\pi} \eta \boldsymbol{\prime} \boldsymbol{\iota}$ - производство, созидание, творчество) и выражает диалектическую связь между структурой и функцией сложной системы. Термин был введен чилийскими учеными Франсиско Варелой и его старшим коллегой и учителем Умберто Матураной в $1973 \Gamma^{1}$.

Автономия означает, что живые системы управляемы эндогенно, они сами себя организуют. И этим модель автопоэзиса отличается от предшествующей ей кибернетической модели Н.Винера и У. МакКаллоха. В последней автономии, по сути, не существует, так как акцент падает на входы (inputs) и выходы (outputs) системы, обрабатывающей информацию. Системы, изучаемые кибернетикой, - это системы по определе-

${ }^{1}$ См.: Князева Е.Н. Автопоэзис мысли // Вестн. Томского гос. пед. ун-та. 2008. Вып. 1 (75). С. 46-54. 
нию гетерономного типа: именно элемент heteros («иное»), а не петля, не autos («само») является для них специфическим и определяющим.

Автономия системы (в данном случае - познающего субъекта как самоопределяющегося существа) означает операциональную замкнутость этой системы. Известно, что открытость системы есть необходимое условие ее самоорганизации. Но системы, достигшие определенного уровня сложности, системы живой природы, человек, общество, не просто открыты, а операционально замкнуты. Такого рода сложные системы (клетка, живой организм, человек, город, страна и т.д.) одновременно и отделены от окружающего мира, и связаны с ним. Их границы подобны мембранным оболочкам, которые являются границами соединения/разделения. Мембрана позволяет такой системе быть открытой миру, брать из окружающей среды нужные вещества и информацию и быть обособленной от него, во всех своих трансформациях и превращениях поддерживать свою целостность, сохранять свою идентичность. Рост сложности систем в мире означает рост степени их избирательности, усиление их операциональной замкнутости.

Лишь маленький ребенок и беспомощный старик растворяют себя в локальной среде, первый - поскольку его Я, собственная идентичность еще не сформирована, второй - поскольку его Я черствеет и разрушается. Они оба - один еще, а другой уже - недостаточно избирательны. Любопытное наблюдение на этот счет можно найти у И.Г. Гёте. Он говорит о том, что младенчество и старость сходны своей бесформенностью. В обоих случаях превалирует диссипативное, рассеивающее, а не организующее, избирательное начало. «Младенчество почти карикатурно; то же скажу и о старости. Младенец представляет собой бесформенную и как бы текучую массу, стремящуюся развиться; старец - массу бесформенную и сухую, которая съеживается и стремится обратиться в ничто» ${ }^{1}$.

Чем более развитой становится человеческая личность, чем в большей степени раскрываются ее творческие способности, тем более избирательной, операционально замкнутой она становится. Такой человек знает, что ему делать, а чем и не стоит заниматься; он умеет отделять зерна от плевел. Творческие личности ценят одиночество, активно нуждаются в нем и даже наслаждаются им, поскольку именно это состояние думать, высказываться, создавать что-то новое, становиться самими собой. Артур Шопенгауэр говорил: «Чем больше человек имеет в себе, тем меньше требуется ему извне, тем меньше могут дать ему другие люди» 2 .

\footnotetext{
${ }^{1}$ Гёте И.В. Собр. соч. в 10 тт. Т. 10. М.: Художественная литература, 1980. С. 125.

${ }^{2}$ Шопенгауэр А. Афоризмы житейской мудрости. М.: Советский писатель, 1990. (репринтное издание, СПб., 1914) С.26.
} 
А Фридрих Ницше подчеркнул: «Тот, кто идет собственным путем, не встретит на нем никого... Никто не придет ему на “помощь”, и со всем, что выпадет ему на долю от опасных мест, случайностей, людской злобы и скверной погоды, он обязан спасаться сам. Его путь - только для него самого...» ${ }^{1}$.

Автономия означает, что личность является самоопределяющейся целостностью. Иначе говоря, личность обладает самогенерирующейся идентичностью, не только поддерживающей себя, но и растущей, саморазвивающейся. Автономная, операционально замкнутая личность является ценным участником научного коллектива, культурного или социального сообщества, поскольку именно от такого рода личности можно ожидать производство креативных идей, производство новых смыслов, которые могут обрести жизнь на уровне социума и привести к становлению новых культурных или социальных образцов.

\section{3. Когнитивные сети как сети коммуникации}

Коммуникация как феномен сложных сетевых структур. Коммуникация, на первый взгляд, - это чисто человеческий феномен. На самом деле только сложные формы вербальной коммуникации являются прерогативой человека. Животные тоже общаются друг с другом, причем весьма интенсивно и изощренно. Коммуникация в живой природе - это обмен информацией между особями, а также в более широком смысле между живым существом и всей окружающей его средой, его жизненным миром - Umwelt, который созидается, конструируется им и творит, конструирует его самого.

Согласно К. Лоренцу, сама жизнь есть когнитивный процесс. Эволюция есть также когнитивный процесс. А всякий сложный феномен познания включает в себя коммуникацию. Коммуникация используется животными для обозначения своей территории, для указания на то, как далеко находятся пищевой ресурс и насколько он богат, для предупреждения сородичей об опасности и т.д. Наиболее древние знаки коммуникации, которые практически выпадают в мире цивилизованного человека, - это запахи. Для собак запахи и распознающий их орган обоняния - основные средства коммуникации.

Прорывные исследования в изучении способов коммуникации животных были проведены Нобелевским лауреатом Карлом фон Фришем. Он изучил сложный телесный язык медоносных пчел, так называемый «танец пчел», посредством которого они сообщают друг другу о местоположении и качестве источников питания.

\footnotetext{
${ }^{1}$ Ницше Ф. Полн. собр. соч. Т.12. М.: Культурная инициатива, 2005. С.144.
} 
О типе используемых ими для коммуникации танцев рассказывает нам П. Ватцлавик. Если обнаруженный пчелой нектар располагается в непосредственной близости, то пчела совершает так называемый круговой танец, который заключается в попеременно совершаемых движениях по полному кругу вправо и влево от источника. Если корм находится на среднем расстоянии от улья, то пчела совершает так называемый серповидный танец, который, если на него посмотреть сверху, похож на рисуемую пчелой восьмерку. Если же корм обнаружен на еще более далеком расстоянии от улья, то пчела совершает так называемый хвостовой танец, который заключается в том, что она продвигается на несколько сантиметров в направлении источника вперед, а затем совершает полукруг направо или налево, возвращаясь к исходному пункту своего движения, а затем повторяет свое движение вперед ${ }^{1}$. Кроме того, фон Фриш установил, что в телесном языке пчел существуют «диалекты». Итальянские медоносные пчелы исполняют хвостовой танец, если источник питания удален более, чем на 40 метров, тогда как у австрийский пчел этот сигнал используется при удалении, по меньшей мере, на 90 метров. Поэтому австрийская пчела, скорее всего, «не поймет» свою итальянскую коллегу и улетит дальше, чем нужно, а итальянская пчела при получении подобного сигнала просто не долетит до источника питания. Язык пчел является эволюционно выработанным и врожденным приспособлением к окружающей среде.

Рассматривая происхождение коммуникации в едином процессе эволюции живой природы и истории культуры человечества, Конрад Лоренц показывает, что коммуникация возникает как побочный продукт ритуализации, развития ритуальных действий. Песни птиц, например, служат не только для обозначения своей территории, но и для привлечения партнеров, поиска самки. Коммуникация является самым древним достижением в ходе развития ритуалов. Вторым достижением было «приручение» действий, их канализация, что привело к развитию социальных форм поведения. Третье достижение - это возникновение новых мотиваций. А четвертое - это запрет на смешение двух видов или двух квази-видов, например, культур и субкультур ${ }^{2}$. В итоге в культурных сообществах коммуникация становится свободным обменом символами.

Интересно обобщить, каковы эволюционные истоки коммуникативной активности живых существ, а в связи с этим каковы основные черты

${ }^{1}$ Cм.: Watzlawick P. Wie wirklich ist die Wirklichkeit? 8. Auflage. München: Piper, 2010. S. 15.

${ }^{2}$ Lorenz K. Die Rückseite des Spiegels. Versuch einer Naturgeschichte menschlichen Erkennens. München: Piper, 1973. S. 275. 
коммуникации в мире животных и чем принципиально она отличается от человеческой коммуникации. Этой теме посвящены пространные исследования, проведенные в последние годы в Институте Конрада Лоренца по изучению эволюции и познания в Альтенберге под Веной ${ }^{1}$.

Во-первых, человек обменивается символами, а животные - сигналами. Это, казалось бы, принципиальное отличие. Символы человеческого мира обладают смыслами. Широкое понимание Umwelt, введенного Икскюлем, склоняют меня к мысли, что живые существа в природе также различают смыслы, творят смыслы.

Во-вторых, в процессе эволюции живых существ возрастает гибкость, флексибельность коммуникации. Умение подстраиваться под изменение ситуации в окружающей среде означает, по сути дела, повышение адаптивных возможностей живых существ, улучшения их способностей выживания. Ответ на сигнал зависит от контекста, от исторического контекста, предыдущего опыта, памяти, кроме того, живые существа могут обучаться через адекватное ситуации действие. Гибкость, пластичность форм коммуникации соответствует такому современному представлению из философии сознания, как ситуационность познания (situated cognition).

Ч. Сноудон, изучая обезьян, приходит к выводу: «Репродуктивно успешные особи - это, по-видимому, те, которые могут быстро отвечать на изменения окружающей среды. Контекстуально гибкая коммуникативная система обеспечивает возможность быстрой корректировки коммуникации в соответствии с изменениями окружающей среды» ${ }^{2}$. В то же время коммуникативные системы не как угодно пластичны, не как угодно могут подстраиваться под окружающий мир. Возможности их подстройки и тонкой настройки на окружающую среду и адресатов их коммуникации определяются формами их телесной организации, способами их двигательной активности и т.п.

В-третьих, восприятие живого существа непосредственно связано с действием, которое творит мир. Восприятие обусловлено особенностями телесной организации живого существа и формами его коммуникации с окружением. Каждый биологический вид в живой природе фактически живет в своем собственном экологическом окружении и соб-

${ }^{1}$ Evolution of Communication Systems. A Comparative Analysis / Ed. By D. Kinbrough Oller and Ulrike Griebel. Cambridge (MA): The MIT Press, 2004; Evolution of Communicative Flexibility: Complexity, Creativity, and Adaptability in Human and Animal Communication / Ed. by D. Kimbrough Oller and Ulrike Griebel. Cambridge (MA): The MIT Press, 2008.

${ }^{2}$ Snowdon Ch. T. Contextually Flexible Communication in Nonhuman Primates // Evolution of communicative flexibility. Cambridge (MA): The MIT Press, 2008. P. 76. 
ственном когнитивном мире. Разные виды живут в различных, часто не пересекающихся мирах восприятия, действия и коммуникации. Какова реальность сама по себе, как таковая, в своей собственной проекции? На этот вопрос ответить не так просто. Конрад Лоренц, например, както заметил, что в немецком языке слово «действительность» Wirklichkeit одного корня с глаголом «действовать» wirken ${ }^{1}$. То, что окружает живое существо, - это не вещи, а, по выражению Я. фон Икскюля, обстоятельства действия Aktion-Dinge. Действительность творится в действии, а способности действовать, формы поведения и коммуникации у особей каждого вида разные. Восприятие и коммуникация создают реальности разные для особей разных видов, разные - для детенышей и взрослых особей, разные - для творческой человеческой личности, которая завтра может быть непохожа на себя сегодняшнюю.

В-четвертых, коммуникация демонстрирует сложность познания и жизни живого существа. А сложность познания выражается в различных формах самоорганизации, кооперативного и когерентного поведения, возможности внезапного, эмерджентного рождения новых форм жизненной активности, познания, коммуникации. Самоорганизация связана с эмерджентностью, которая является важнейшим понятием в современной теории сложных адаптивных систем, каковыми являются биологические системы, человек - его тело и сознание, - социальные системы, информационные сети и т.п. Конрад Лоренц не любил слово «эмерджентность» и предложил слово фульгурация (от лат.: fulguratio сверкание молнии) для обозначения феномена рождения чего-то принципиально нового в эволюции.

Сборка субъектов как механизм построения сетевых структур. В последнее время в российском научном сообществе, главным образом под влиянием В.Е. Лепского, началось обсуждение проблемы сборки субъекта или сборки субъектов, если имеются в виду способы вписывания индивидуального субъекта в социальную и культурную среду и его отношения с другими субъектами. Одна из пионерских работ «Проблема сборки субъектов в постнеклассической науке» на эту тему была опубликована в Институте философии РАН в 2010 году². Сама постановка проблемы весьма необычна. Проблема сборки субъектов непосред-

1 Лорени, К. Кантовская концепция а priori в свете современной биологии // Эволюция. Язык. Познание. М.: Языки русской культуры, 2000. С. 21.

${ }^{2}$ См. в этом сборнике прежде всего статью: Лепский B.E. Эскиз структуры параметров сборки субъектов в их дестриптивной модели // Проблема сборки субъектов в постнеклассической науке /Отв. ред. В.И. Аршинов и В.Е. Лепский. М.: ИФ РАН, 2010. C. $185-217$. 
ственно касается обсуждаемой в этой главе проблемы интерсубъективности с точки зрения энактивизма.

Знание принципов коэволюции сложных систем позволяет раскрыть основные смыслы нового понятия «сборка субъекта» (или «сборка субъектов). Прежде всего, очевидно, что сборка субъекта неотделима от сборки мира. Под сборкой мира можно понимать способы рождения и самоподдержания в нем целостных образований, интеграции частей в целое при построении сложных систем, или, как сказал бы С.П. Курдюмов, нелинейного синтеза частей в целое. Почему нелинейного? Потому что в мир, наполненный сложными коэволюционирующими системами, нелинеен. Это означает, что следствия не просчитываемы из причин: малые причины могут вызывать несоизмеримые, огромные, далеко идущие и масштабные последствия, а относительно большие причины могут никуда не сдвигать систему, не вызывать видимых следствий, если система находится в устойчивом состоянии. Нелинейность связей между вещами и событиями мира определяет нелинейность способов сборки, нелинейного синтеза простого в сложное.

Можно говорить об изоморфности мира и каждой его частей, о том, что сложность мира сказывается на сложности его части, а из сложности части вырастает сложность мира. Гегель говорил: «Каков человек, таков и мир», но можно сказать также, что «Каков мир, таков и человек».

Матрешечность, или масштабная инвариантность (фрактальность), строения мира имеет эволюционный и пространственный, и темпоральный смысл. Вложенными, фрактально организованными являются и пространственные структуры, и циклы эволюции.

Говоря о сборке субъекта, необходимо прояснить и смыслы субъективности, в том числе напомнить философские смыслы понятия субъекта. В субъекте (человеке как субъекте, коллективном человеческом субъекте, мире и каждой вещи как субъекте) есть моменты самодвижения, автономии, обращенности на самого себя, рефлексии. По Аристотелю, субъект сам по себе неподвижен, но вместе с тем он сам движется. По Гегелю, субъект конституируется как сам процесс размышления над самим собой. Способ действия субъекта есть нарезание, расщепление, усмотрение различий посредством введения отрицания в поток чувственных восприятий. Эта способность к самодвижению, присущая субъекту, есть чистая негативность.

Таким образом, мир в его сборке и человек в его сборке находятся в отношении взаимной детерминации и взаимного построения. С этой точки зрения непростое понятие habitus, введенное Марселем Моссом (1872-1950) и развитое Пьером Бурдье (1930-2002), становится вполне естественным и понятным. Фактически речь идет о сборке индивиду- 
ального субъекта социального действия, которая осуществляется под влиянием и по образу структур социального мира, в котором он действует. Habitus - это структура ума, набор приобретенных схем, верований, вкусов, диспозиций индивидуального сознания. Диспозиции индивида к его восприятию, мышлению и действию, то есть его habitus, есть объективации социальных структур на уровне индивидуальной субъективности. Индивид втягивает в себя социальный мир, он, как и мир, строится через диспозиции сознаний индивидов, служащих узелками для роста социальных структур. Структура индивидуального сознания изоморфна структурным условиям мира, в которых она возникает.

Сборка субъектов происходит через их синергийное взаимодействие. Американский антрополог Рут Бенедикт (1887-1948), которая прославилась благодаря своему сочинению "Patterns of Culture” (1934), развива-

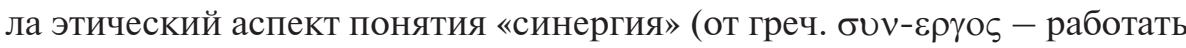
вместе). Синергия в ее антропологическом и этическом смысле раскрывает тайну сборки субъектов в социальной среде, когда разделение труда или работа команды (teamwork) дает неоспоримое преимущество какойлибо социальной группе (или государству) и выдвигают ее на экономическом рынке, политической арене или геополитическом пространстве.

Социальные образования с высокой синергией, иными словами, с оптимальной, правильной сборкой, сводят агрессию до минимума и доводят сотрудничество до максимума. Они отличаются большим доверием, меньшей централизацией (т.е. большим внутренним разнообразием) и большим чувством ответственности. Герман Хакен, рисуя картину желаемого самоорганизующегося общества, отмечает: «Каждый отдельный человек вносит вклад в коллективное поведение, которое действует как параметр порядка и в конечном счете - совершенно в духе синергетики - затягивает на этот путь все большее количество индивидов, даже, выражаясь несколько резко, «порабощает» их в своих действиях... В качестве общего знаменателя может быть взят как существенный $п р и н-$ цип ответственности Ханса Йонаса в самом широком смысле. Достойное человека самоорганизующееся общество может продолжительно существовать только тогда, когда каждый поступает так, как если бы он в рамках своей собственной деятельности был ответственен за целое» ${ }^{\text {. }}$

Психолог Абрахам Маслоу подчеркивал, что в обществе с высокой синергией «заведен такой порядок вещей, при котором действия индивидуума, направленные на достижение личной выгоды, выгодны обществу в целом... Такое общество лишено агрессивности не потому, что люди неэгоистичны и ставят социальные интересы выше своих лич-

${ }^{1}$ Хакен Г. Самоорганизующееся общество / Перевод Е.Н. Князевой // Синергетическая парадигма. Вып. 6. М.: Прогресс-Традиция, 2010. 
ных, а потому, что при данном социальном устройстве эти интересы

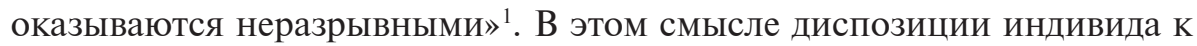
действию, познанию и творчеству вливаются в подвижки социальной структуры, работают на нее, стимулируя обратным влиянием действия каждого индивида.

Стоит указать на еще одну важную характеристику процесса сборки субъектов. Сборка субъектов становится выгодной для социальной среды и для социальных сообществ, если она осуществляется спонтанно, без внешнего принуждения, путем самоорганизации. Тайну эффективной сборки субъектов можно попытаться раскрыть при помощи понятия хитрости коллективного разума.

Как известно, в своей философии истории Гегель описал феномен хитрости мирового разума (List der Vernunft). История достигает своей цели независимо от воли и конкретных действий отдельных индивидов, как будто за спинами и головами социальных акторов стоит некий мировой разум, который независимо, а иногда и вопреки воле людей, выводит историю в нужное, предустановленное русло.

Используя аналогию с идеей Гегеля, известный специалист в области эволюционной эпистемологии Э. Эзер говорит о существовании такого феномена как хитрость коллективного разума. К этому можно добавить, что, возможно, существует хитрость сети по отношению к отдельным ее элементам и даже узам: сеть «знает» больше, чем отдельный ее элемент. Жестокая конкуренция между индивидами в социальных или когнитивных сетях оборачивается их плодотворной кооперацией, эгоизм членов преодолевается, превращаясь в энергию социального или когнитивного целого, в синергию социального творчества и инновирования.

Хитрость коллективного разума, по Эзеру, - это 2 :

- принуждение к самовыражению и представлению самого себя. Каждый член некоторой группы вынужден представлять себя перед другими членами этой группы. Семья или иная малая социальная группа представляет собой, согласно этому взгляду, такой «аппарат принуждения», посредством которого человек смог развиться в так называемом поле преодоления своей звероподобной сущности;

- принуждение создать условия, при которых другие тебя не могут не заметить;

- принуждение к формированию внутреннего самопонимания всей группы. Это принуждение к совместному самопредставлению группы

${ }^{1}$ Цит. по: Вайнцвайг П. Десять заповедей творческой личности. М.: Прогресс, 1990. C. 66.

2 Oeser E. Psychozoikum. Evolution und Mechanismus der menschlichen Erkenntnisfähigkeit. Berlin und Hamburg: Paul Parey, 1987. S. 128. 
в области научного исследования предстает в виде соответствующей целевой установки группы;

- принуждение к представлению себя вовне. Хитрость коллективного разума состоит в превращении конкуренции в кооперацию.

Каждая часть (человек как субъект) обладает своей собственной территорией. Творческий ум неограничен, автономен, определяет сам себя, требует для своего развития некой среды для нестесненного развития, в этом смысле можно говорить об экологии творческого разума. Аналогичным образом Эзер говорит об экологии коллективного разума - об определенных ландшафтах информации и знания в процессе научной деятельности, где господствует и правит коллективный разум, или, в представлении Т.Куна, парадигмальное сознание.

Возникающее в результате сборки целое (целостная эволюционирующая структура) обладает свойством эмерджентности. Выделяют следующие критерии эмерджентности:

- неаддитивность, т.е. величина целого не равна сумме величин частей (в этом же заключается и холистический эффект);

- новизна;

- принципиальная непредсказуемость;

- макродетерминация (влияние части на целое и через целое);

- нередуцируемость (целого к части и части целого к целому и части, какими они были до возникновения целостности).

Глубокое понимание принципов коэволюции, нелинейного синтеза частей в устойчиво эволюционирующее целое, открываемых теорией сложных систем, может и должно лечь в основу эффективной сборки субъектов социального действия. Коэволюция - это «искусство жить вместе», содействуя утверждению толерантности и сохранению разнообразия в глобализирующихся сообществах. Коэволюция (устойчивое совместное развитие) как партнерство означает:

а) жить друг с другом, а не против друг друга;

б) жить так, чтобы не уменьшать шансы других, в том числе будущих поколений, жить также хорошо;

в) заботиться о тех, кто беден и бесправен, а также о состоянии окружающей среды, расширять круг нашего внимания, сочувствия и заботы (толерантность и экологическое сознание).

Ф. Капра отмечает: «Партнерство - весьма существенная особенность устойчивых сообществ... Со времен появления первых ядерных клеток 2 миллиарда лет назад жизнь на Земле прошла через неуклонно усложняющиеся формы кооперации и совместной эволюции. Партнер- 
ство - тенденция объединяться, устанавливать связи, жить друг в друге и сотрудничать - одна из важнейших отличительных черт жизни. В человеческих сообществах партнерство означает демократию и расширение прав личности, поскольку каждый член сообщества играет в ней важную роль. Комбинируя принцип партнерства с динамикой изменений и развития, мы можем метафорически использовать совместную эволюцию применительно и к человеческим сообществам» ${ }^{1}$.

«Искусство жить вместе» означает стимулирование толерантности к другому образу жизни/другим людям и поддержание разнообразия в глобализирующихся обществах.

Коэволюция есть «искусство жить в едином темпомире», не свертывая, а поддерживая и развивая разнообразие на уровнях элементов и отдельных подсистем. А значит, нужно культивировать у каждого чувство ответственности за целое в плюралистичном и объединенном мире.

«Искусство жить вместе» - это искусство поддержания единства через разнообразие, взращивания самости, своего неповторимого личностного Я путем одновременно обособления от среды и слияния с ней. Каждый элемент (личность, семья, этнос, государство) сложной коэволюционирующей целостности операционально замкнут, поддерживает свою идентичность. Каждый элемент творит себя через целое и преобразует целое, творя самого себя. Он должен забыть себя, чтобы найти себя, обнаружить свое сродство с миром, чтобы познать самого себя, построить самого себя по-новому.

Интерсубъективность в процессе познания и коммуникации. Ключевой принцип, на котором строится энактивистский подход к интерсубъективности, заключается в том, что живой организм (человек как субъект познания) является центром активности мира, он вовлечен в мир телесно, нейронально, перцептуально, интеллектуально, он встраивается в динамику окружающей его среды и преобразует эту среду в соответствии со своими нуждами. В своей когнитивной деятельности он строится во взаимодействии с другими индивидами, посредством них и через них. Интерсубъективность вырастает в каждый момент из взаимодействия двух или более субъектов.

В одной из своих последних работ Ф. Варела обратил внимание на то, что энактивность ${ }^{2}$ познания связана, в первую очередь, именно с

${ }^{1}$ Капра Ф. Паутина жизни. Новое научное понимание живых систем. Киев: София; М.: ИД «Гелиос», 2002. С. 323.

${ }^{2}$ Князева E.Н. Энактивизм: концептуальный поворот в эпистемологии // Вопросы философии. 2013. № 10. С. 91-104; Князева Е.Н. Энактивизм: новая форма конструктивизма в эпистемологии. М., СПб.: Центр гуманитарных инициатив, 2014. 
межличностными, интерактивными взаимодействиями каждого из нас. «Познание есть порождающая энактивная взаимная детерминация Я Другой» ${ }^{1}$.

Интерсубъективность - это не просто сотрудничество между взаимодействующими индивидами и координация их ментальной деятельности; интерсубъективность следует рассматривать в рамках понятий нерепрезентатизма, энактивизма, телесности, вдействования в мир и в друг друга и взаимного отелеснивания (интеркорпоральности). Мы моделируем верования и намерения других людей, с которыми мы имеем дело, как будто мы находимся в их ситуации. За такой процесс ответственны в мозге так называемые зеркальные нейроны.

Прежние концептуальные рамки, в которых отсутствует процессуальная, ситуационная, телесная, интерактивная и энактивная составляющие, ныне подвергаются серьезной критике.

Во-первых, наша ментальность - это не просто внутреннее царство, которое отделено от внутреннего мира других эпистемическим заливом, который мы можем переплыть посредством логических заключений, выводов, проекций. Мы в принципе скрыты друг от друга, поэтому чтобы понять другого или других, мы должны поставить себя на его или их место.

Во-вторых, оценивая действия других и стремясь их понять, мы обычно занимаем позицию «третьего лица», т.е. внешнего наблюдателя. Это недостаточно, мы должны быть встроены в саму ситуацию, в сам процесс: наблюдения со стороны недостаточно, мы должны быть во взаимодействии или даже вдействовании в друг друга, а это и есть позиция энактивизма.

В-третьих, нам следует избегать картезианской ошибки, что тело есть всего лишь передаточный прибор, напротив необходимо рассматривать взаимные связи телесно воплощенных когнитивных агентов.

В-четвертых, традиционные подходы к социальному познанию недостаточны и подвержены критике, поскольку в них не учитывается, что различные когнитивные способности проистекают друг от друга, определенным образом связаны и эволюционируют на протяжении человеческой жизни.

В качестве альтернативного выдвигается энактивистский взгляд на интерсубъективность:

\footnotetext{
${ }^{1}$ Varela F. Steps to a Science of Inter-being: Unfolding the Dharma Implicit in Modern Cognitive Science // Ed. by Bachelor S., Claxton G. and Watson G. The Psychology of Awakening: Buddhism, Science and Our Day to Day Lives, Rider/Randon House. P.81.
} 
1. Социальное понимание, хотя и базируется на взаимодействиях между людьми, является индивидуальным делом каждого из нас. Оно строится на автономии каждого и благодаря ей.

2. Интерсубъективность существенным образом опирается на определенную телесную воплощенность коммуницирующих индивидов.

3. Намерения индивидов могут казаться непрозрачными и скрытыми, но на самом деле они выражаются в действиях, поэтому могут быть поняты другими.

4. Цели и намерения других людей не являются пред-данными и статичными, они генерируются и трансформируются в процессе взаимодействия. Социальное познание и социальное действие означают возможность самокорректировки своих действий в зависимости от реакций других и в зависимости от изменяющейся ситуации социального взаимодействия.

Производство смыслов - это не разовый акт, а процесс. Смыслы сосоздаются в процессе взаимодействия партнеров, они открываются все новые и новые по мере развертывания, и углубления этого взаимодействия. Производства смыслов в социальном взаимодействии - это процесс с открытым концом, это настоящее приключение, которое подстегивается синергией взаимодействующих личностей.

С представлением об энактивности познания тесно связано представление о телесности познания. Можно сказать, что принимая эту новую исследовательскую программу, саму эпистемологию мы можем назвать телесно ориентированной.

Существуют телесные нити, управляющие разумом. Психосоматические связи строятся по принципу нелинейной циклической причинности. Тело и душа, мозг и сознание находятся в отношении циклической, взаимной детерминации. Отстаивая единство тела и духа, М. МерлоПонти отмечал, что дух есть «иная сторона тела. Он прочно внедрен в тело, поставлен в нем на якорь». Телесно восприятие человеком самого себя. По его словам, «Я не перед своим телом, Я не в своем теле, скорее Я и есть мое тело». То, что познается и как познается, зависит от телесной организации живого существа и встраивания его в мир. Таксы, например, имеют удлиненное тело и поэтому приспособлены для охоты в норах.

Структуры восприятия и мышления зависят от «синергий тела», от сенсомоторного опыта, которому соответствуют определенные нейронные структуры. Когнитивные структуры могут быть соотнесены с определенными сенсомоторными схемами.

Телесное познание есть движение и действие. Воспринимающий и мыслящий ум есть тело в движении. По словам Анри Бергсона, «на- 
ша мысль изначально связана с действием. Именно по форме действия был отлит наш интеллект». Как подчеркивают де Джегер и ди Паоло, «движение есть центр телесной активности» ${ }^{1}$. Мы видим не глазами, а руками и ногами. Знания не пассивно приобретаются организмами как когнитивными агентами, но активно строятся ими. Живые организмы как целостные системы активно взаимодействуют с элементами окружающей среды, конструируя ее и находясь в процессе конструирования самих себя под ее влиянием.

Наш мир восприятия и мышления не ограничивается нашей кожей и кончиками наших пальцев. Мы распределены в окружающем мире, в нашем узком социуме, который строится нами и посредством наших мыслей и наших действий. Еще М. Мерло-Понти обратил внимание на то, что для слепого его палка перестает быть просто объектом, она не воспринимается им как внешний объект, она становится областью его собственной чувствительности, расширяя объем и активный радиус касания, и выступает как механизм, компенсирующий зрение 2 . Несколько заостряя смысл этого представления, можно сказать, что для слепого палка становится частью его самого.

Аналогичным образом, для ученого его компьютер, его флешка, его книга конспектов или же его экспериментальные приборы и установки - это продолжение его самого. Потеря этих дополнений - это потеря ученым самого себя, которая может вызвать в нем неимоверные страдания. Субъективность человека продлена и продолжена в мир его вещейпроцессов, в мир его социальных отношений.

Не мы в мире, а мир в нас. Мы строимся от окружающего мира, который непрерывно строится и достраивается нами. Umwelt - это созданный нами окружающий мир, обратно влияющий на нас самих. Umwelt - это и наш микросоциум, мир наших непосредственных социальных связей и отношений. Живой организм и окружающая среда совместно и взаимно конституируют друг друга. Эта теоретическая позиция становится в настоящее время достаточно популярной и получает название extended mind $^{3}$.

Наш мир - это, скорее, не мир вещей, а мир действий, мир наших поведенческих актов и откликов на эти акты. Часто обсуждается простейший пример - восприятие нами мягкости губки. Мягкость губки не находится в ней самой, она обнаруживается нами в нашем действии

${ }^{1}$ De Jaegler H., Di Paolo E. Parpicitatory Sense-making. An Enactive Approach to Social Cognition // Phenomenology and Cognitive Sciences. 2007. Vol. 6. P. 489.

${ }^{2}$ См. об этом: Fuchs T., Jaegher de H. P. 472.

${ }^{3}$ Одна из флагмановских статей принадлежит перу Э. Кларка и Д. Чалмерса: Clark A., Chalmers D.J. The Extended Mind. // Analysis. 1998. Vol. 58. P. 7-19. 
и благодаря ему, в том, как губка отвечает на наше активное действие, на сжатие, производимое соответствующими движениями нашего тела (наших ладоней или пальцев).

В социальном мире, мире социальных взаимодействий говорят вслед за Мерло-Понти об интеркорпоральности, которая необходима для социального понимания и производства смыслов. Наши целенаправленные или непроизвольные телесные действия - хватания, указание, передача из рук в руки, касания, движения навстречу или, напротив, отстранения, являются чрезвычайно значимыми действиями. Особое значение имеет весь арсенал невербальной коммуникации - язык телодвижений и поз, жестов, интонаций голоса, мимики и движений глаз, культурных касаний, о котором замечательно рассказывает в своих книгах Г.Е. Крейдлин ${ }^{1}$. Интонации голоса и телесные движения нередко говорят больше и несут в себе больше смыслов, чем сами слова. И, конечно, намеренное прекращение коммуникации (не произнесение приветствия «Здравствуйте!) несет несравнимо больший смысл для знающих друг друга людей, чем беглое «Зрасьте!».

Коммуницируют между собой телесно организованные субъекты, и коммуникация их как именно таковых означает рождение смысла. «Фактически смыслы возникают, устанавливаются, изменяются и т.п. через межличностную координацию движений. И, наоборот, движения становятся межличностными, будучи координированными через попытки понимания друг друга, которые направляются также усилиями создать и наладить способы понимания друг друга»².

Говоря о важности интеркорпоральности для возникновения интерсубъективности, следует подчеркнуть также, что люди как когнитивные существа или как акторы социального действия являются гибкими, пластичными, флексибельными системами. История их предыдущих социальных коммуникаций, хотя и во многом определяет сегодняшнее общение и достижение понимания, но не жестко: они изменяются в процессе жизни и взаимодействия и могут выходить на новый уровень взаимного понимания и личностного соприкосновения или же, напротив, полностью или частично терять интерес друг к другу и/или способность достижения согласия. Необходимо учитывать также, что действия и социальные взаимодействия приобретают свою собственную жизнь и изменяются в зависимости от изменяющейся ситуации (ситуативность достижения интерсубъективности).

\footnotetext{
${ }^{1}$ См., например: Крейдлин Г.Е. Невербальная семиотика. М.: Новое литературное обознание, 2004.

${ }^{2}$ Fuchs T., Jaegher de H. P. 471.
} 
Эмпатия в когнитивных сетевых структурах. Человек как участник социальных взаимодействий не просто наблюдает других людей, строя сложные межличностные отношения или занимаясь литературным, поэтическим, актерским творчеством, он развивает в себе способность вчувствования, эмпатии. Изучению феномена эмпатии уделяется ныне большее внимание, тем не менее, здесь остается еще немало неясного.

Эмпатия является одновременно и основой креативных способностей человека, и способом восприятия, понимания и создания красоты, и внутренним стержнем для морального действия. Эмпатия - тот узелок, через который соединяются истина, красота и добро. В художественном и отчасти научном творчестве способность вчувствования это способность слиться с природным и/или социальным миром, войти с ним в резонанс, чтобы открыть в нем, а тем самым и в себе самом, что-то новое. В восприятии красоты - это основа незаинтересованного любования. Этическое поведение начинается тогда и постольку, когда и поскольку человек научается чувствовать радость (или горе) другого как свою собственную радость (или горе), о чем писал Адам Смит в своем опусе «Theory of Moral Sentiments».

Эмпатия означает способность выйти из самого себя и посмотреть на самого себя со стороны, зазеркалить себя, на что не способны животные, которые сливаются со своим окружением, со своим Umwelt. Современное открытие в нейронауке говорит, что за эту способность ответственны так называемые зеркальные нейроны. А вместе с тем это высшая способность человеческого духа. Человек отстраняется от самого себя и сливается с миром или с другим человеком (или общностью людей), тем самым он открывает что-то ранее неизвестное в мире и одновременно перестраивает самого себя. Путем расставания с собой он себя находит. Пересаживая часть самого себя в личность другого, отдавая самого себя (тем самым создается как бы симбиозная личность), он находит самого себя подлинного, обновляет и развивает себя. Не боясь потерять свою идентичность, он ее обретает и укрепляет. В мире, в другом (или в других), в не-Я он узнает самого себя, свое Я.

Если параметры внешнего воздействия со стороны социальной среды соответствуют собственным параметрам личности как сложной самоорганизующейся системы, то имеет место феномен резонанса. Резонанс с точки зрения теории сложных самоорганизующихся систем (синергетики) - это топологически правильное воздействие на психику, мозг и тело человека (поскольку есть психосоматическая связка, то воздействуя на тело, мы воздействуем на психику, и наоборот), т.е. воздействие на них пусть и малое, но конфигурационно правильное, симметричное. Это приводит к многократному усилению креативной 
активности личности, раскрытию огромных потенций человеческой психики и сознания.

Для того, чтобы познать сложные явления природного и социального мира, нужно построить сложную структуру на поле мозга и сознания. И то, и другое, рассуждая по большому счету, строится по единому закону: структуры мозга и структуры действительности конгруэнтны. Ведь и всякая природная среда, и среда мозга открыты и нелинейны, а стало быть, являются «полигоном» для разыгрывания процессов самоорганизации. Человек является результатом, продуктом эволюции природы, и, будучи ее собственным порождением, способен познавать мир и себя в нем. Не на этом ли пути следует искать решения главной проблемы для человеческого разума - познаваемости мира, - которую Макс Планк называл чудом?

Человек не чужд миру, его возвращение в лоно мира, понимание смыслов коллективной деятельности в социуме в пиковых моментах творческого экстаза и озарения есть возвращение к своей собственной природе, к своим истокам, к своему собственному происхождению.

Этот резонанс иначе можно описать как эмпатию, т.е. вчувствование (Einfühlung), вживание, вдействование в мир, энактивность, перевоплощение, перенесение и идентификация. Эмпатия означает чувствование мира или другого человека как самого себя, способность поставить себя на место познаваемой вещи, рисуемого или воспеваемого объекта. Парадоксально при этом то, что максимальное творческое самовыражение субъекта соответствует максимальной объективности, подлинности результатов творчества. Иначе говоря, максимум личностного, человеческого, субъективного в творце снимает это личностное или даже начисто уничтожает его, и дает подлинно объективную картину бытия.

Благодаря современной методологии познания сложных адаптивных систем и сетевых структур мы стоим на пороге разгадывания тайн таких сложных явлений человеческого познания, креативной деятельности и коммуникации, как интерсубъективность, интеркорпоральность, духовная и творческая синергия, эмпатия.

\section{Литература:}

1. Добронравова И.С. Синергетика: становление нелинейного мышления. Киев: Лыбидь, 1990.

2. Гёте И.В. Собр. соч. в 10 тт. Т. 10. М.: Художественная литература, 1980.

3. Капра Ф. Паутина жизни. Новое научное понимание живых систем. Киев: Софияб М.: ИД «Гелиос», 2002.

4. Князева Е.Н. Автопоэзис мысли // Вестн. Томского гос. пед. ун-та. 2008. Вып. 1 (75). C. 46-54. 
5. Князева E.H. Энактивизм: концептуальный поворот в эпистемологии // Вопросы философии. 2013. № 10. С. 91-104.

6. Князева Е.Н. Энактивизм: новая форма конструктивизма в эпистемологии. М., СПб.: Центр гуманитарных инициатив, 2014.

7. Князева Е.Н., Куркина Е.С. Мыслитель эпохи междисциплинарности // Вопросы философии. 2009, № 9. С. 116-131.

8. Крейдлин Г.Е. Невербальная семиотика. М.: Новое литературное обознание, 2004.

9. Мертон Р. Непреднамеренные последствия преднамеренного социального действия // Социологический журнал. 2009. № 2. С.15.

10. Мне нужно быть. М.: КРАСАНД, 2010.

11. Морен Э. Принципы познания сложного в науке XXI века. / Пер. с франц. Е.Н.Князевой. // Вызов познанию: Стратегии развития науки в современном мире. М.: Наука, 2004.

12. Лепский В.E. Эскиз структуры параметров сборки субъектов в их дестриптивной модели // Проблема сборки субъектов в постнеклассической науке /Отв. ред. В.И. Аршинов и В.Е. Лепский. М.: ИФ РАН, 2010. С. 185-217.

13. Лорени, K. Кантовская концепция а priori в свете современной биологии // Эволюция. Язык. Познание. М.: Языки русской культуры, 2000.

14. Ницще Ф. Полн. собр. соч. Т.12. М.: Культурная инициатива, 2005.

15. Олескин А.В. Биополитика. Курс лекций. М., 2007.

16. Хакен Г. Самоорганизующееся общество / Перевод Е.Н. Князевой // Синергетическая парадигма. Вып. 6. М.: Прогресс-Традиция, 2010.

17. Шопенгауэр А. Афоризмы житейской мудрости. М.: Советский писатель, 1990. (репринтное издание, СПб., 1914).

18. Штомпка П. Инновации и инноваторы. // Социология. Анализ современного общества. М., 2005.

19. Barabási A. $-L$. Linked: How Everything is Connected to Everything Else and What It Means for Business, Science and Everyday Life. N.-Y.: Basic Books, 2014.

20. Barabási A.-L. The Network Takeover // Nature Physics. 2012. Vol. 8. P. 14-16.

21. Clark A., Chalmers D.J. The Extended Mind. // Analysis. 1998. Vol. 58. P. 7-19.

22. De Jaegher H., Di Paolo E. Participatory Sense-making. An Enactive Approach to Social Cognition // Phenomenology and the Cognitive Sciences. 2007. Vol. 4. N 4. P. 485-507.

23. Evolution of Communication Systems. A Comparative Analysis / Ed. By D. Kinbrough Oller and Ulrike Griebel. Cambridge (MA): The MIT Press, 2004.

24. Evolution of Communicative Flexibility: Complexity, Creativity, and Adaptability in Human and Animal Communication / Ed. by D. Kimbrough Oller and Ulrike Griebel. Cambridge (MA): The MIT Press, 2008.

25. Holland J.H. Hidden Order: How Adaptation Builds Complexity. Readings (MA): Addison-Wesley Publishing Company, 1995.

26. Lorenz K. Die Rückseite des Spiegels. Versuch einer Naturgeschichte menschlichen Erkennens. München: Piper, 1973.

27. Maturana H.R. Self-consciousness: How? When? Where? // Constructivist Foundations. 2006. Vol. 1. N 3.

28. Morin E. Les sept savoirs nécessaires à l'èducation du futur. Paris: UNESCO, 2000. 
29. Morin E. Le complexus, ce qui est tissé ensemble // Rŭda Benkirane. La Complexité, vertiges et promesses. Paris: Le Pommier, 2002.

30. Oeser E. Psychozoikum. Evolution und Mechanismus der menschlichen Erkenntnisfдhigkeit. Berlin und Hamburg: Paul Parey, 1987.

31. Snowdon Ch. T. Contextually Flexible Communication in Nonhuman Primates // Evolution of communicative flexibility. Cambridge (MA): The MIT Press, 2008.

32. Varela F. Steps to a Science of Inter-being: Unfolding the Dharma Implicit in Modern Cognitive Science // Ed. by Bachelor S., Claxton G. and Watson G. The Psychology of Awakening: Buddhism, Science and Our Day to Day Lives, Rider/Randon House. P.71-89.

33. Watzlawick P. Wie wirklich ist die Wirklichkeit? 8. Auflage. München: Piper, 2010.

\section{Олена Князєва. Когнітивні мережі: інтерактивність, інтерсуб'єктивність, синергія}

У статті обговорюються деякі властивості когнітивних мереж в контексті сучасних досягнень науки про мережі (Network Science). Саме дослідження мережевих структур і їх дивовижних властивостей надає сьогодні нового потужного імпульсу розвитку теорії складних систем (синергетики). Аналіз пізнавальних процесів з точки зору виникаючих в них мережевих структур не тільки сполучається з уже існуючими в когнітивній науці і епістемології поняттями (когнітивна ніша, когнітивна карта, когнітивна когерентність i т.п.), але і привносить деякі нові аспекти в розуміння інтерактивності, інтерсуб'єктивності, синергії в пізнанні і творчості, емпатії.

Ключові слова: автономія, дзеркальні нейрони, інтерсуб'єктивність, когнітивні мережі, когнітивні німі, партисипаційне виробництво смислів, мережеві структури, складність, емпатія, енактивізм.

\section{Helena Knyazeva. Cognitive Networks: Interactivity, Intersubjectivity, and Synergy}

Some properties of cognitive networks are discussed in the article in the context of the modern achievements of the network science. It is the study in network structures and their surprising properties that gives a new impetus to the development of the theory of complex systems (synergetics). The analysis of cognitive processes from the point of view of the network structures that arise in them not only fits with such concepts already existing in cognitive science and epistemology, as cognitive niches, cognitive maps, cognitive coherence, etc.), but also brings some new aspects to the understanding of interactivity, intersubjectivity, synergy in cognition and creative activities, empathy.

Key words: autonomy, mirror neurons, intersubjectivity, cognitive networks, cognitive niches, participatory sense-making, network structures, complexity, empathy, enactivism. 
Елена Николаевна Князева - доктор философских наук, профессор Школы философии Факультета гуманитарных наук Национального исследовательского университета «Высшая школа экономики» в Москве (Россия), академик Международной академии наук о системах и кибернетических наук.

E-mail: helena_knyazeva@mail.ru

Helena Knyazeva is Doctor habil. in Philosophy, Professor of the School of Philosophy of the Faculty for Humanities at the National Research University Higher School of Economics in Moscow, Russia.

E-mail: helena_knyazeva@mail.ru 